\title{
Oligodendrocyte Precursor Quantitation and Localization in Perinatal Brain Using a Retrospective Bioassay
}

\author{
Gregory E. Gonye, Arthur E. Warrington, Joseph A. DeVito, and Steven E. Pfeiffer \\ Department of Microbiology, University of Connecticut School of Medicine, Farmington, Connecticut 06030-2105
}

\begin{abstract}
Several late stages of the oligodendrocyte $(\mathrm{OL})$ developmental lineage can be identified immunologically in the newborn rat brain. However, $\mathrm{OL}$ lineage-specific markers are not avallable for the detection of the less mature, yet determined, $\mathrm{OL}$ precursors. We have developed a retrospective bioassay, combining limiting dilution analysis with a novel culture system, that quantitatively assesses the developmental potential in vivo of phenotypically undefined OL precursors in order to (1) demonstrate their existence, (2) estimate their total number in the premyelinated rat brain, and (3) demonstrate their presence in regions distal to germinal zones at times previously predicted to be devoid of such cells. Between embryonic day $(E) 21$ and postnatal day (P) 0 , cells determined to become oligodendrocytes increase in frequency $\sim 5$-fold in the whole brain (from one precursor for every 365 cells to 1 in 74 ), and $\sim 2.5$-fold in the telencephalon (from 1 in 298 to 1 in 115). From these data it is calculated that a pool of $\sim 10^{6}$ phenotypically undefined cells are present in the newborn brain that are able to differentiate into $\mathrm{OL}$ in vitro. Further, by applying this assay to tissue samples of subdomains of the developing cerebellum, we have demonstrated that such cells are present in large numbers as early as E20 in regions sparsely populated with cells expressing the blastic neural cell marker ganglioside $G_{03}$, suggesting that they migrated to this position as a pre- $G_{03}$ expressing cell. These results significantly change the predicted ontogeny of the oligodendrocyte lineage and should fuel the ongoing search for these early OL precursors.
\end{abstract}

[Key words: oligodendroblast, gangliosides, development, limiting dilution analysis, migration, culture]

The final stages of the macroglial lineage leading to the production of oligodendrocytes (OL), the myelinogenic cells of the CNS in mammals, have been described through the application of a battery of lineage-specific markers encompassing antigenic, biochemical, and molecular technologies (Pfeiffer et al., 1993). An early OL progenitor is defined by the expression of developmentally regulated gangliosides such as $\mathrm{G}_{\mathrm{T} 3}$ and $\mathrm{G}_{\mathrm{D} 3}$ (Raff et

\footnotetext{
Received Sept. 27, 1993; revised Feb. 22, 1994; accepted Mar. 2, 1994.

We thank Drs. A. Gard and R. Bansal for intellectual input and manuscript reviewing, K. Murray for her expert technical assistance with the cell culture, and A. Gonye for assistance in preparation of the manuscript. This work was supported by the National Institutes of Health (NS10861) and the National Multiple Sclerosis Society (RG2181-A4).

Correspondence should be addressed to Dr. Steven Pfeiffer, Department of Microbiology, University of Connecticut School of Medicine, Farmington, Connecticut 06030 .

Copyright (C) 1994 Society for Neuroscience $0270-6474 / 94 / 145365-08 \$ 05.00 / 0$
}

al., 1983; Levine and Goldman, 1988; Reynolds and Wilkin, 1988; Dubois et al., 1990). Pro-oligodendroblasts, the immediate proliferative progenitor of OL, are identified by the expression on the cell surface of the developmental antigen POA prior to the expression of sulfatide and galactosyl cerebroside (GalC) (Dubois-Dalcq, 1987; Gard and Pfeiffer, 1989, 1990; Bansal et al., 1992; Warrington and Pfeiffer, 1992). These cells subsequently become postmitotic and differentiate into OL per se, identified by the expression of sulfatide, GalC, and $2^{\prime}, 3^{\prime}$ cyclic nucleotide $3^{\prime}$-phosphohydrolase (CNP), and later by myelin basic protein (MBP) and proteolipid protein.

Less information is available for precursors in the OL lineage prior to these stages, for which stage-specific and cell typespecific markers are not available. The monoclonal antibody A2B5 has proven valuable in the study of glial progenitors in the optic nerve (Raff et al., 1983). Since this structure is devoid of neuronal cell bodies, cells reacting with A2B5 could be definitively identified as OL progenitors. Similarly, where culture conditions allowed the survival of only a limited number of cell types, the use of cross-reacting antisera could still lead to fairly definitive phenotypic assignments (Hardy and Reynolds, 1991). However, this is not the case for more complex tissues such as the brain, in which at any given time early in development heterogeneous cell populations include neuroblasts, neurons, astrocytes, oligodendroblasts, and immature OL, all of which are recognized by A2B5 and express $\mathrm{G}_{\mathrm{D} 3}$.

Thus, there is an ongoing search for new early markers specific to the OL lineage. For example, subpopulations of developing neural cells expressing NG2, a chondroitin-sulfate proteoglycan antigen, differentiate into OL in culture (Levine et al., 1993). However, although NG2 expression is initially more restricted to the OL lineage than either $\mathrm{G}_{\mathrm{D} 3}$ or $\mathrm{A} 2 \mathrm{~B} 5$ antigens, a population of cells outside of the presumptive white matter is also labeled that does not differentiate into OL. Another potential marker for early $\mathrm{OL}$ precursors is the $\alpha$ receptor for platelet-derived growth factor (PDGF- $\alpha$ R; Pringle et al., 1992). PDGF- $\alpha$ R RNA is initially restricted to a small number of cells in embryonic rat brain within the germinal zones distal to the periventricular regions believed to be the source of proliferative and migratory cells giving rise to $\mathrm{OL}$ postnatally. Since in vitro, among the macroglia, only cells of the OL lineage were shown to express PDGF- $\alpha$ R (Hart et al., 1989; McKinnon et al., 1990), Pringle et al. (1992) suggested that the PDGF- $\alpha$ R RNA ${ }^{+}$cells they saw early in development in vivo were OL precursors. PDGF- $\alpha \mathrm{R}$ RNA-cxpressing cells, essentially undetectable in postnatal day 0 (P0) cerebellum, were found scattered throughout all regions of the cerebellum by P3. However, at a similar developmental age (P2) Warrington and Pfeiffer (1992) demonstrated the pres- 
ence of relatively large numbers of regionally organized OL by staining live cerebellar sections with the monoclonal antibodies $\mathrm{O} 4$ and $\mathrm{O} 1$. Thus some pro-oligodendroblasts (O4+O1- cells) and $\mathrm{OL}\left(\mathrm{Ol}^{+}\right.$cells), detectible in vivo, do not appear to be expressing PDGF- $\alpha$ R RNA. Although both OL precursors and OL continuc to cxpress PDGF- $\alpha \mathrm{R}$ in culturc (Hart ct al., 1989; McKinnon et al., 1990), perhaps only a subpopulation of OL precursors are accumulating PDGF- $\alpha$ R RNA at any given time in vivo.

Evidence has also been presented for the presence in cultures derived from rat white matter of determined OL "preprogenitors" arising prior to the later, identifiable stages (Grinspan et al., 1990; Hardy and Reynolds, 1991). After first depleting cell populations of identifiable OL lineage cells by antibody-mediated complement lysis, cells remained that were capable of differentiating into antigenically identifiable OL progenitors and mature OL. Further evidence for early determined OL precursors comes from studies utilizing retroviral vectors (Luskin et al., 1988). Reporter genes were introduced randomly into cells at early embryonic stages, and the subsequent appearance of cells with characteristics of OL lineage cells was studied as a function of development. A single cell could be infected as early as embryonic day 14 (E14), which subsequently gave rise only to OL. Thus, it is clear that an OL precursor population does exist very early in CNS development.

An alternative means of quantifying precursor populations in a complex mixture utilizes limiting dilution analysis (LDA) (Lefkovitz and Waldmann, 1979), an approach used extensively in the study of the immune system (Sharrock et al., 1990). This technique involves seeding cultures with decreasing numbers of unidentifiable immature cells, allowing time for their development, and then assaying for the presence of identifiable, more mature cell types that could have arisen only from the precursors. LDA can in principle be applied to any lineage for which a random population of single cells can be generated, and has been used to investigate the microglial and oligodendroglial lineages (Barbarese et al., 1981; Richardson et al., 1993).

Prcvious estimates of the OL lineage pool (Barbarese et al., 1981; Gard et al., 1988) resulted in a model of OL ontogeny requiring a relatively small pool of precursors to undergo a period of rapid cell division around the time of birth in order to generate the numbers of OL appearing postnatally. Recent improvements in our culture system, specifically, a culture system of perinatal rat brain cells that supports the highly efficient survival, proliferation, and differentiation of early OL precursors at very low (limiting) plating densities, and the availability of new reagents recognizing OL lineage cells, make this model seem unlikely. This has allowed us to demonstrate the existence of phenotypically undefined OL precursors prior to birth, quantify their numbers in perinatal rat brain, and determine their relative position in developing cerebellum.

A preliminary report of some of these data has been presented in abstract form (Gonye et al., 1989).

\section{Materials and Methods}

Cell dissociation and culture. Single-cell suspensions were prepared by mechanical and enzymatic dissociation (Gard et al., 1988) (minced with a single-edged razor blade, trypsinized in EBSS-HEPES at $37^{\circ} \mathrm{C}$ for 30 $\mathrm{min}$, and triturated in the presence of $80 \mu \mathrm{g} / \mathrm{ml}$ DNase) from prenatal and neonatal telencephala (including structures rostral to the thalamus after removal of the olfactory bulbs and meninges) or the whole brain (including brainstem, medulla oblongata, cerebellum, midbrain, and cerebral hemispheres). Basic culture media consisted of Dulbecco's Modified Eagle's Medium containing $10 \% \mathrm{v} / \mathrm{v}$ fetal calf serum $(10 \%$ FCS/DMEM).

Immunofluorescence microscopy. Unfixed cultures were immunolabeled with the monoclonal antibody O4 (Sommer and Schachner, 1982), as described by Bansal et al. (1989, 1992), in order to identify cells specific to the final stages of the OL lineage. OL were identified by immunolabeling with an anti-CNP polyclonal antiserum after fixation with $4 \%$ buffered paraformaldehyde ( $10 \mathrm{~min}$ at room temperature) and pcrmcabilization with $0.05 \%$ saponin ( 5 min at room tcmpcraturc) (Bansal and Pfeiffer, 1985). Nuclei were stained by the addition of $4^{\prime}-6,6$ diamidino-2-phenylindole (DAPI) to the secondary antibody solution (1:104 final dilution).

Phenotypically enriched populations. Phenotypically enriched subpopulations of these cells were obtained by combining antibody-mediated complement lysis and immunopanning (Gard and Pfeiffer, 1989; Warrington et al., 1993). These included early OL progenitors defined by the expression of gangliosides (recognized by the monoclonal antibody A2B5) in the absence of POA expression, pro-oligodendroblasts defined by reactivity with the monoclonal antibody $\mathrm{O} 4$ in the absence of GalC expression, and OL defined by the expression of GalC (reactivity with the monoclonal antibody O1) (Warrington et al., 1993).

Astrocyte feeder layers. Feeder layers of OL-free astrocytes were produced (Noble and Murray, 1984) by shaking OL lineage cells from mixed neural cultures $\left(200 \mathrm{rpm}, 16 \mathrm{hr}, 37^{\circ} \mathrm{C}\right)$ (McCarthy and DeVellis, 1980) and subculturing the remaining cells $1: 5$ onto polylysine-coated $(25 \mu \mathrm{g} /$ $\mathrm{ml}, 30 \mathrm{~min}, 37^{\circ} \mathrm{C}$ ) plastic culture dishes. These cells were treated with $20 \mu \mathrm{M}$ cytosine arabinoside (AraC) for $48 \mathrm{hr}$, fed drug-free media for $24 \mathrm{hr}$, further treated with AraC for another $48 \mathrm{hr}$, irradiated to inhibit proliferation (2000 rad), and seeded into microcultures at $\sim 5 \times 10^{4} /$ well (96-well plate). The media were changed and cells were allowed to recover at least $48 \mathrm{hr}$ in $10 \% \mathrm{FCS} / \mathrm{DMEM}$ prior to the addition of primary neural cell populations. Purity was determined by immunofluorescence microscopy carried out directly in microwells for OL lineage cells (O4, anti-MBP, or anti-CNP; Bansal and Pfeiffer, 1985; Bansal et al., 1988, 1989) and astrocytes (anti-glial fibrillary acidic protein; Lee et al., 1984). After staining, the well bottoms were punched out and a $12 \mathrm{~mm}$ coverslip was placed over a drop of glycerol/phosphate-buffered saline (PBS) $(9: 1, \mathrm{pH} 8.6)$ containing $0.1 \%(\mathrm{w} / \mathrm{v}) 1,4$-diazobicyclo $(2,2,2)$ octane to inhibit fading of fluorescence (Johnson et al., 1982) during epifluorescent microscopic analysis. Only astrocyte populations devoid of OL lineage cells $(<0.001 \%)$ were used in further studies.

Limiting dilution analysis culture system. The medium was removed from astrocyte feeder cultures and replaced with $100 \mu \mathrm{l}$ of " $\mathrm{M}^{+}$" media [DMEM supplemented with the serum substitute $\mathrm{Mito}^{+}$at $1 \times$ concentration (supplied as $1000 \times$ stock, Collaborative Research Inc., Cambridge, MA), $1 \%$ FCS, and $15 \mathrm{~nm}$ triiodothyronine]. Single-cell suspensions were serially diluted in $100 \mu \mathrm{l}$ of $\mathrm{M}^{+}$, and microcultures $(60-120$ cultures per seeding density) were seeded with $0-500$ cells per culture in $100 \mu \mathrm{l}$. Cultures were maintained in a humidified incubator at $37^{\circ} \mathrm{C}$, $5 \% \mathrm{CO}_{2}$ for $15-18 \mathrm{~d}$ to allow OL progenitors present in the initial input populations to differentiate into $\mathrm{CNP}^{+} \mathrm{OL}$, identified by immunohistochemistry for CNP (below). Half of the media was exchanged with fresh $\mathrm{M}^{+}$every $3 \mathrm{~d}$

Immunohistochemistry for $O L$ in microcultures. Culture plates were randomized and encoded by an investigator unfamiliar with the study and prepared as for microculture ELISA (Gard et al., 1988). Briefly, cultures were spin fixed in $0.25 \%$ glutaraldehyde at $4^{\circ} \mathrm{C}, 100 \times g$ for 15 min, and rinsed with PBS (pH 7.4). Nonspecific binding sites were blocked by overnight incubation in $100 \mathrm{~mm}$ glycine/1\% BSA in PBS at room temperature; cultures were incubated with rabbit anti-CNP (Bansal et al., 1988; 1:1000 in 3\% NGS/PBS) for $1 \mathrm{hr}$ at room temperature, washed four times with PBS, and primary antibody binding detected using the corresponding HRP-ABC kit (Vector Laboratories Inc., Burlingame, CA) according to the manufacturer's protocols with $0.05 \% \mathrm{w} / \mathrm{v}$ diaminobenzidine plus $0.01 \% \mathrm{H}_{2} \mathrm{O}_{2}$ in $50 \mathrm{~mm}$ Tris- $\mathrm{HCl}$, $\mathrm{pH} 4.7$, as substrate (Correa et al., 1988). The reaction was carried out in the dark until a suitable signal-to-noise ratio was obtained in high-density $\mathrm{OL}$ control cultures $(\sim 30 \mathrm{~min})$. The microwells were filled with $400 \mu \mathrm{l}$ of PBS to minimize distortion caused by the curve of a meniscus and labeled cells were visualized using bright-field optics on an invertedstage microscope.

Limiting dilution analysis. The statistical basis of this analysis has been described in detail (Lefkovits and Waldmann, 1979) and has been applied to the OL lineage (Barbarese et al., 1983; Gard et al., 1988). A 
range of cell input values and large numbers of test cultures (60-120 per input value) yield statistically significant results. The zero term of the Poisson distribution, $F_{o}=e^{-u}$, or its logarithmic form, $-\ln F_{o}=u$, can be explained in terms of responding and nonresponding cultures where $F_{o}$ is defined as the fraction of the nonresponding cultures (cultures producing no colonies of mature $\mathrm{OL}$ ) and $u$ is defined as the mean number of precursor cells per culture, a constant for any seeding cell input value, assuming a random distribution. A graph of $-\ln F_{o}$ versus cell input is prepared, and the slope of the line generated from a leastsquares fit of the data represents the frequency of OL precursors, the theoretical cell input for which the mean number of precursors is one $(u=1)$. In order to count only proliferative precursors, a positive (responding) microculture was defincd as one containing cight or morc $\mathrm{CNP}^{+}$cells in close proximity to each other. This would require a single OL precursor and its offspring to undertake a minimum of three divisions before differentiation. Each data set was tested for goodness of fit to linearity by a $\chi^{2}$ analysis, and $95 \%$ confidence intervals of the slopes were calculated.

Microdissection of cerebellar slices. Rats at E20, P0, P1, P7, P17, and 12 weeks of age (adult) were used for microdissection analysis. The cerebellum and hindbrain were separated from the forebrain and 300 $\mu \mathrm{m}$ slices were made with a Mcllwain tissue chopper (Warrington and Pfeiffer, 1992). Midline cerebellar slices (two or three slices in young animals, six to eight slices in older animals) were further dissected to obtain an "inner" cerebellum, consisting of the lower central cerebellum and any attachment to the underlying hindbrain via the superior medullary velum or the cerebellar peduncles, and an "outer" cerebellum, consisting of the tips of the folia just slightly beyond the invaginations between individual folia. Thus, the outer cerebellum consisted predominantly of the molecular, Purkinje, and granule layers, with little if any presumptive white matter tracts. In older animals the outer cerebellum consisted of that tissue beyond the white matter of the folia. During tissue dissociation (described above), young cerebellum presented no problems with debris, but adult samples often required two centrifugations through a $4 \%$ BSA gradient.

\section{Results}

Development of a quantitative limiting dilution analysis for the OL lineage

Quantitative LDA has two critical requirements (Lefkovits and Waldmann, 1979). First, input cells representative of an initial population must be distributed randomly into a large number of parallel test cultures. This was accomplished using a dissociation method (Gard et al., 1988) that generates a viable singlecell suspension consisting of greater than $60 \%$ of the starting population present in brain at perinatal ages.

Second, each culture receiving a single cell of the desired phenotype must produce a positive response. False negative results can be generated from a number of biological and technical sources such as insufficient or inappropriate media components, poor cell proliferation and survival, requirement for additional cell types, and inefficient detection of offspring. We have developed a novel culture system to address a number of these influences specific to the OL lineage.

Clearly, a successful LDA requires $100 \%$ plating efficiency for the cell type of interest, even at the low cell densities required at limiting dilution. This goal was initially expected to be difficult to achieve with dissociated brain cells. However, the use of a modified culture medium and a live astrocyte feeder substratum appears to accomplish this.

Neural cells plated directly onto poly-D-lysine (PDL)-treated plastic or glass in DMEM supplemented with fetal calf serum develop into a stratified culture consisting of a monolayer of astrocytes with microglia and OL lineage cells growing on top of this layer (Abney et al., 1981). Under these conditions, OL lineage cells do not survive well at low plating densities $\left(<10^{4}\right.$ cells $/ \mathrm{cm}^{2}$; Gard et al., 1988). To quantitate the advantage gained
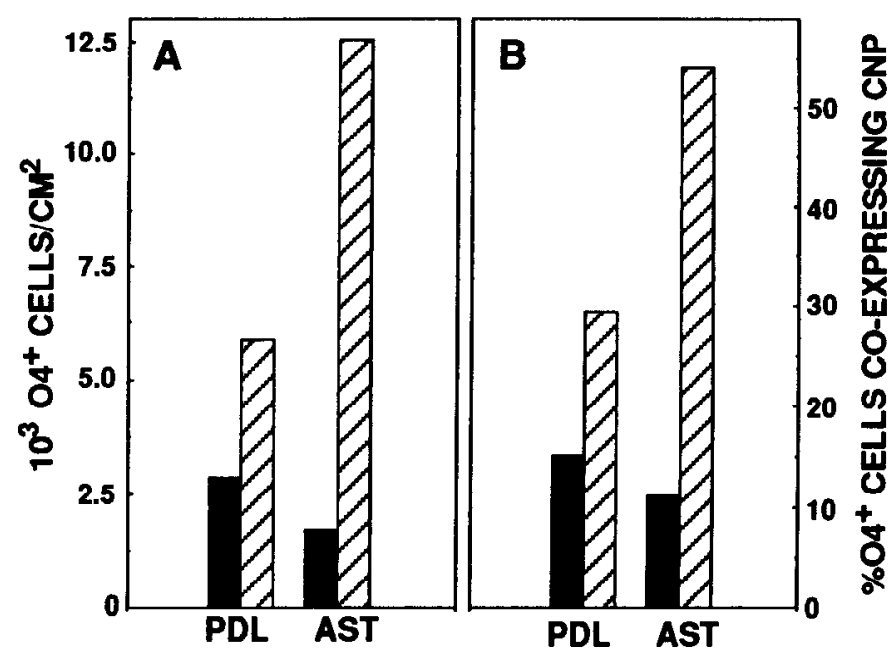

Figure 1. $\mathbf{M}^{+}$media and a live astrocyte substratum greatly increase oligodendrocyte production. The number of late $\mathrm{OL}$ lineage cells $\left(\mathrm{O}^{+}\right)$ produced by culturing mixed neural cells in the presence of $10 \% \mathrm{FCS} /$ DMEM (solid bars), or in $\mathbf{M}^{+}$media (hatched bars), with poly-D-lysine $(P D L)$ or live astrocytes $(A S T)$ as the substratum were determined $(A)$. Values represent the product of the calculated total cell number (DAPIstained nuclei) per $\mathrm{cm}^{2}$ and the percentage of $\mathrm{O}^{+}$cells of the total after $6 \mathrm{~d}$ in vitro. The relative rate of differentiation was also determined $(B)$ Data are expressed as the percent of $\mathrm{O}^{+} \mathrm{OL}$ (cells coexpressing CNP) in the same cultures used in $A$. PDL cultures were seeded at $1.25 \times 10^{5}$ cells $/ \mathrm{cm}^{2}$. $\Lambda \mathrm{ST}$ cultures were seeded at $1.25 \times 10^{4} \mathrm{cells} / \mathrm{cm}^{2}$. Values were generated by counting $>600$ cells over duplicate coverslips for each condition.

by the use of astrocyte feeder layers (Noble and Murray, 1984), dissociated neonatal rat brain cells were plated at decreasing cell densities in 10\% FCS/DMEM onto either PDL-treated glass coverslips or onto live astrocyte monolayers. The cultures were then grown under identical conditions for a sufficient time to allow OL development, and tested for the presence of OL lineage cells by immunofluorescent microscopy using the $\mathrm{O} 4$ monoclonal antibody. Whereas cultures initiated directly on the PDLtreated glass required a density $>1 \times 10^{4}$ cells $/ \mathrm{cm}^{2}$ (4000 cells/ microwell) to produce $\mathrm{O}^{+}$cells, cells plated onto astrocyte monolayers generated OL precursors from as few as 50 cells/ $\mathrm{cm}^{2}$ ( 20 cells/microwell).

Next we investigated media contributions affecting OL production. OL precursors developing in vitro in media containing high levels of fetal calf serum can differentiate into a glial fibrillary acidic protein (GFAP)-expressing cell (historically named the type 2 astrocyte), which does not go on to express OL-specific antigens (Raff et al., 1983). If OL precursors are cultured in defined media, devoid of mitogens, they do not proliferate but differentiate immediately (Noble and Murray, 1984; Raff et al., 1985). Both of these effects would lower the probability that any individual precursor cell would go on to produce an OL clone. We have addressed this by replacing the fetal calf serum in the growth media with $\mathrm{Mito}^{+}$, a commercially available serum substitute cocktail. Cultures were initiated on either PDL-treated tissue culture plastic or astrocyte feeder layers, with either $10 \%$ FCS/DMEM or $\mathrm{M}^{+}$(a reduced serum medium utilizing Mito $^{+}$; see Materials and Methods), at either $1.25 \times 10^{5}$ cells $/ \mathrm{cm}^{2}$ for PDL cultures or $1.25 \times 10^{4}$ cells $/ \mathrm{cm}^{2}$ for feeder layer cultures. Development was allowed to continue for $6 \mathrm{~d}$. Effects on the appearance of OL lineage cells were determined by measuring 

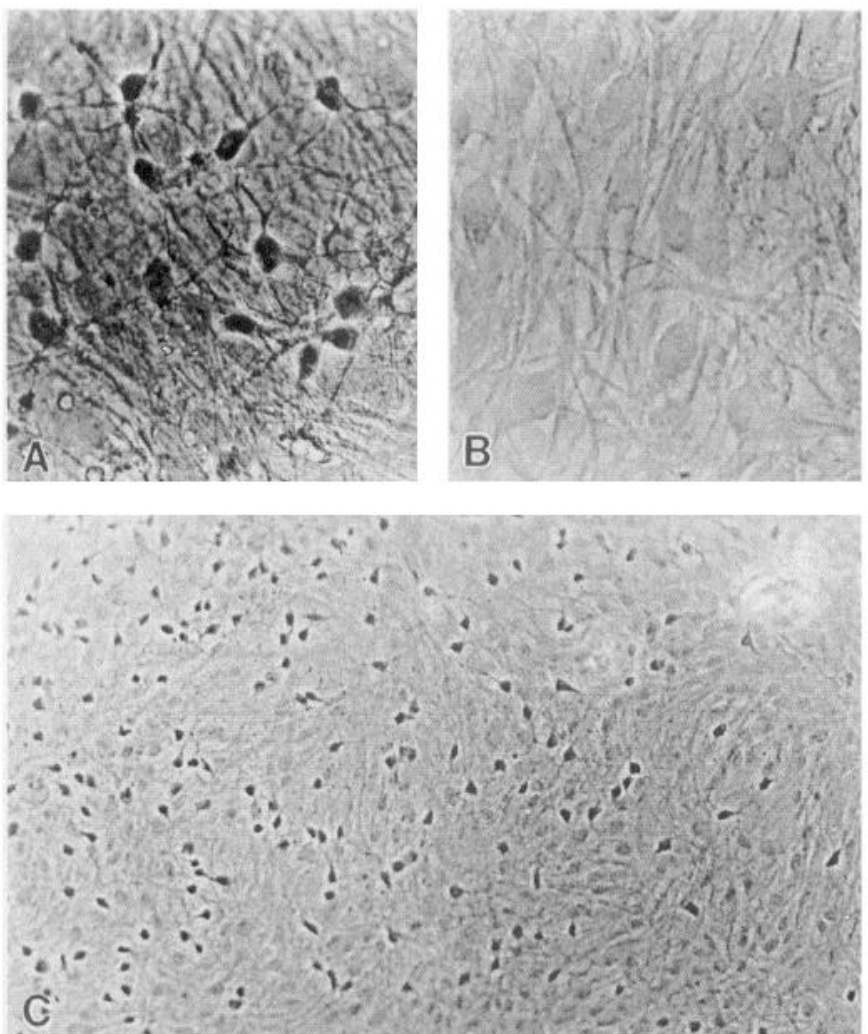

Figure 2. Offspring of OL precursors developing in the LDA system expressing CNP. Mixed E21 brain cells were plated onto astrocyte feeders in $\mathrm{M}^{+}$at limiting dilution, allowed to develop for $15 \mathrm{~d}$, and then stained for CNP. Individual stained cells exhibit classic OL morphology with highly branched processes $(A, C)$, and were easily distinguished from the weakly stained astrocyte feeder layer $(B$, an field adjacent to $A$ devoid of OL lineage cells). Fields were photographed using brightfield optics. Magnification: $A$ and $B, 300 \times ; C, 100 \times$.

total cell density, the number of identifiable OL lineage cells $\left(\mathrm{O}^{+}\right)$, and the number of $\mathrm{OL}\left(\mathrm{O}^{+} \mathrm{CNP}^{+}\right)$in the culture (Fig. 1). There was a twofold increase in total $\mathrm{O}_{4}^{+}$cell number in cultures plated on PDL-treated glass when the FCS was reduced from $10 \%$ to $1 \%$ and replaced with $\mathrm{Mito}^{+}$(Fig. 1 $A$, PDL). Further, the rate of OL differentiation was elevated, as seen by the twofold increase in the percent of $\mathrm{O}^{+}{ }^{+}$cells coexpressing $\mathrm{CNP}$ during the same time frame (Fig. $1 B$, PDL). We conclude that by simply replacing the standard media with $\mathrm{M}^{+}$we had increased OL output approximately fourfold in the first $6 \mathrm{~d}$ after plating.

Since $\mathrm{M}^{+}$was mitogenic for the astrocytes present in the cultures grown on PDL (data not shown), it was important to determine the growth characteristics of OL precursors in the presence of the vast excess of astrocytes provided by the feeder layer. In this experiment it was possible to start with a much lower input density (10-fold less than above) due to the increased cell survival obtained from plating on live astrocytes. After 6 $\mathrm{d}$, the number of $\mathrm{O}^{+}$cells arising on astrocyte feeder layers increased fivefold over parallel 10\% FCS-containing cultures, from $1.7 \times 10^{3} \mathrm{O}^{+}$cells $/ \mathrm{cm}^{2}$ in the presence of $10 \%$ FCS to $12.5 \times 10^{3}$ in $\mathrm{M}^{+}$(Fig. 1A, AST). Differentiation also occurred even more rapidly in cells growing in $\mathrm{M}^{+}$on astrocytes than on PDL; $54 \%$ of $\mathrm{O}^{+}$cells expressed $\mathrm{CNP}$ after $6 \mathrm{~d}$ in $\mathrm{M}^{+}$, compared to $11 \%$ of $4^{+}$cells in $10 \%$ FCS at the same time (Fig. $1 B$, AST). By combining the use of live astrocytes as the sub-
Table 1. Stage-specific development in the LDA culture system

\begin{tabular}{ll} 
Phenotype & $\begin{array}{l}\text { Cell input } \\
\text { required } \\
\text { for OL produc- } \\
\text { tion }\end{array}$ \\
\hline $\mathrm{A} 2 \mathrm{~B} 5+\mathrm{O}^{-}$ & $30 \pm 14$ \\
$\mathrm{O}^{+}{ }^{+} \mathrm{O} 1^{-}$ & $7.5 \pm 3.5$ \\
$\mathrm{O}^{+}$ & 500
\end{tabular}

Phenotypically enriched populations were generated by immunopanning from P5 telencephala. Individual populations consisted of $\mathrm{A} 2 \mathrm{~B} 5{ }^{+} \mathrm{O}^{-}(\sim 70 \%$ OL progenitors, $30 \%$ other neural lineages), $\mathrm{O}^{+} \mathrm{Ol}^{-}$( $>95 \%$ pro-oligodendroblasts), and $\mathrm{Ol}^{+}(\sim 50 \%$ immature OLs, $\sim 50 \%$ other cell types of which $\sim 6 \%$ were prooligodendroblasts). Six cultures were initiated with various cell inputs for each data point, allowed to develop for $15 \mathrm{~d}$, and then tested for the presence of OL by CNP immunocytochemistry. The input required to produce OL in all six cultures were determined. This value represents the relative capacity of the population to generate OL clones in this culture system. The data are the average of two experiments.

stratum with $\mathrm{M}^{+}$media, we have addressed two known weaknesses in previous OL culturing methods, poor initial survival and media effects, and have been able to increase OL lineage cell production $\sim 40$-fold (compare FCS/PDL to $\mathrm{M}^{+} / \mathrm{AST}$ from 10-fold less cells, Fig. 1A).

An additional source of false negative tests can arise from the assay for the offspring of the originally plated precursors. Previous LDAs of the OL lineage used assays requiring relatively large numbers of OL for positive results, that is, radioimmunoassay (Barbarese et al., 1981) and ELISA (Gard et al., 1988). It is possible that small clones would go undetected in such assays. Therefore, the LDA culture system was next combined with an immunohistochemical detection technique to allow for the processing of the large numbers of cultures required for quantitative limiting dilution analysis and visualization of individual stained cells. In order to test the efficiency of this assay, individual OL clones were generated. Microcultures were seeded with decreasing amounts of input cells for E21 brain until an input density, 130 cells $/ \mathrm{cm}^{2}$, was established which consistently produced a combination of OL-containing and OL-negative cultures after 15-18 d development. At this limiting input each positive culture had only a single OL clone. This allowed us to optimize the staining procedure. Individual $\mathrm{CNP}^{+}$cells with characteristic OL morphologies could easily be seen under brightfield optics (Fig. 2A,C) against a low background of astrocyte staining (Fig. $2 B$, an adjacent field in the same culture as $2 A$ devoid of $\mathrm{CNP}^{+} \mathrm{OL}$ ). OL in cultures seeded at limiting input, statistically the offspring of a single OL precursor, occupied only a section of the culture, had clear radial gradients of cell density away from the center of the clone, and varied in number from tens to thousands of cells.

\section{Relative proliferative capacity of specific $O L$ lineage phenotypes in the LDA culture system}

The LDA culture system was further characterized in order to determine if the increased OL product was the result of aberrant proliferation of normally postmitotic OL, as well as to investigate the proliferative capacity of the known mitotic stages of the OL lineage. Phenotypically enriched populations of the OL lineage, that is, $\mathrm{OL}$ progenitors $\left(\mathrm{A} 2 \mathrm{~B} 5^{+} \mathrm{O} 4^{-}\right.$), pro-oligodendroblasts $\left(\mathrm{O}^{+}{ }^{+} \mathrm{Ol}^{-}\right)$, and $\mathrm{OL}\left(\mathrm{Ol}^{+}\right)$were immunoisolated from P5 rat telencephala and seeded in microwells with decreasing cell input. The number of input cells required to consistently generate a series of six OL-containing cultures was determined 


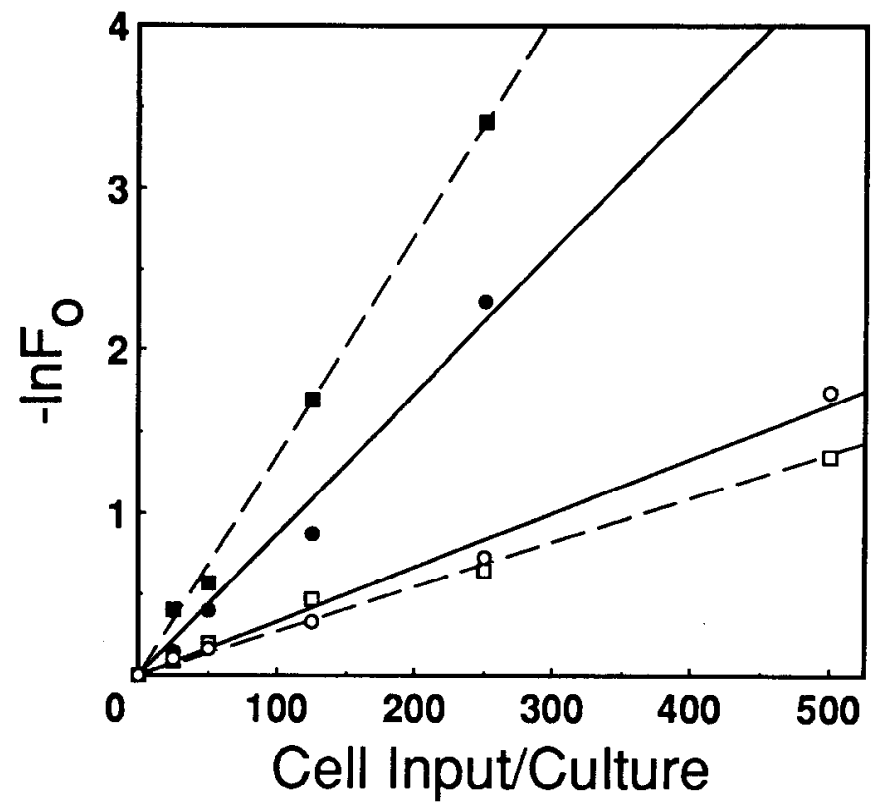

Figure 3. Limiting dilution analysis of OL precursors from perinatal rat brain. The natural logarithm of the fraction of nonresponding cultures was graphed versus cell input. Sixty to one hundred and twenty wells were used for each data point. Analyses were performed at E21 $(O, \square)$ and $\mathrm{PO}(\boldsymbol{Q}, \square)$ with cell populations generated from either whole brain $(\square, \square$, dashed lines) or telencephalon $(0,0$, solid lines). Lines were fitted by the least-squares error method. The slope of these lines is the calculated frequency of OL precursors in the initial cell population (Table 2).

for each population. OL progenitors and pro-oligodendroblasts produced $\mathrm{CNP}^{+}$clones at very low cell input numbers, whereas the OL population required greater than 17-67-fold more cells, respectively (Table 1 ). This is consistent with the proliferative capacity of these cell types in vivo (Gard and Pfeiffer, 1990; Warrington and Pfeiffer, 1992), suggesting that the OL generated in the LDA culture system are from progenitors and not due to the proliferation of more mature $\mathrm{OL}$. The differences in seeding requirements between the $\mathrm{A} 2 \mathrm{~B}^{+}{ }^{+} \mathrm{O}_{4}^{-}$and $\mathrm{O}_{4}^{+} \mathrm{O} 1^{-}$cells probably arise from the nonspecificity of the A2B5 monoclonal antibody on unfixed cells. In contrast, the $\mathrm{O} 4$ monoclonal antibody remains specific for cells of the OL lineage when used on unfixed cells. One hour following immunoisolation, $>95 \%$ of the prooligodendroblast population selected was $\mathrm{O}_{4}^{+} \mathrm{O}^{-}$, indicating they were essentially all of the OL lineage. In contrast, only $\sim 70 \%$ of the $\mathrm{A} 2 \mathrm{~B} 5^{+} \mathrm{O}^{-}$cells were immature stages of the OL lineage (Warrington et al., 1993), the remaining cells probably belonging to neuronal lineages since A2B5 also recognizes neuroblasts (Eisenbarth et al., 1979). The cell population isolated with the $\mathrm{O} 1$ antibody also contains many cells of neuronal lineages, since $\mathrm{O} 1$ identifies Purkinje cells and other small neurons in unfixed brain slices (Warrington and Pfeiffer, 1992). One hour following $\mathrm{O} 1$-mediated immunoisolation for OL, $6 \%$ of the cells were $\mathrm{O}^{+}{ }^{+} \mathrm{O}^{-}$pro-oligodendroblasts that slipped through the isolation procedure. These cells could easily account for the $\mathrm{CNP}^{+}$clones produced with the "OL" population at an input of 500 cells per culture (Table 1).

\section{Determination of $O L$ precursor frequency in perinatal rat brain}

Fulfillment of the LDA requirements outlined above will result in "single-hit events," leading to a linear relationship between
Table 2. OL precursor frequency and total pool size

\begin{tabular}{llrlrr} 
& & $\begin{array}{l}\text { Frequency } \pm \\
95 \% \text { confidence } \\
\text { interval } \\
\text { Cell source }\end{array}$ & Age & \multicolumn{1}{c}{$\begin{array}{l}\text { Per cell } \\
\text { unit }\end{array}$} & $\begin{array}{l}\text { Total OL } \\
\text { precursor } \\
\text { pool }\end{array}$ \\
\hline Whole brain & E21 & $2.74 \pm 0.41$ & & $1 / 365$ & $2 \times 10^{5}$ \\
& P0 & $13.58 \pm 0.89$ & $1 / 74$ & $10 \times 10^{5}$ \\
Telencephalon & E21 & $3.35 \pm 0.39$ & $1 / 298$ & $1 \times 10^{5}$ \\
& P0 & $8.73 \pm 1.74$ & $1 / 115$ & $2.5 \times 10^{5}$
\end{tabular}

Frequencies were determined by calculating the slope of the line generated from least-squares error analysis of the LDA data (Fig. 3). Confidence intervals were calculated as described by Lekovits and Waldmann (1979). The per cell unit represents the reciprocal of frequency values. Pool sizes were estimated from the product of the total cell number for each tissue used (Table 1 from Gard et al., 1988) and the frequency determined by LDA.

the natural logarithm of the fraction of negative wells of the total tested $\left(\ln F_{o}\right)$ and the number of precursors seeded per well (u). In contrast, failure to achieve one or more of these rcquircments results in "multihit" or "multitarget" events, both of which generate nonlinear relationships between $\ln F_{o}$ and $u$ that are not useful for determining progenitor frequency. Multihit events occur if more than one cell of the limiting cell type is required for a positive test result, as is the case if cells are dying (i.e., low plating efficiency) or if the detection method generates false negatives. Multitarget events occur if more than one cell type is required to produce a positive test result, as in the case of helper cells.

LDA was used to determine the frequency of OL precursors present in rat brain at E21 and PO. Whole brain or telencephalon single-cell suspensions were used to seed microcultures at various cell input values. For each value, the natural $\log$ of the fraction of total wells not containing OL was determined, after allowing $18 \mathrm{~d}$ for proliferation and differentiation (Fig. 3). The excellent adherence to linearity demonstrates that the only limiting component of our system was the OL precursors, and that if a culture received a single precursor, it survived and produced sufficient $\mathrm{CNP}^{+}$offspring to generate a positive result. This is paramount to $100 \%$ plating efficiency for this cell type in this culture system.

From these data a frequency value was generated for each data set by determining the slope of a line through the origin from a least-squares fit (Table 2). The frequency of OL precursors in the whole brain increased from $\sim 1$ in 365 cells at E21 to $\sim 1$ in 74 cells at $\mathrm{PO}(\sim 5$-fold $)$. During the same time interval in the telencephalon, OL precursors increased from $\sim 1$ in 298 cells at E21 to $\sim 1$ in 115 cells at P0 $(\sim 2.5$-fold $)$.

\section{Total $O L$ lineage pool size in perinatal rat brain}

The total OL precursor pool size, which includes any cell capable of giving rise to an OL clone greater than eight $\mathrm{CNP}^{+}$cells, was estimated by calculating the product of the frequency and the total number of cells from which the tested population originated (Table 2). In E21 brain this pool was $\sim 2 \times 10^{5}$ cells, onehalf of which were in the telencephalon. In P0 brain this pool was $\sim 1 \times 10^{6}$ cells, a fourth of which $\left(\sim 2.5 \times 10^{5}\right)$ were in the telencephalon. Since pro-oligodendroblasts (identified directly by immunolabeling with $\mathrm{O} 4$ ) are not yet present in the telencephalon at E21 (Gard and Pfeiffer, 1989), the entire population of OL progenitors at this age must consist of less mature, undefined phenotypes. In contrast, at P0 $0.5 \%$ of the total cells in 
Table 3. Localization of OL precursors in developing cerebellum

\begin{tabular}{llllrll} 
& \multicolumn{7}{l}{ Cell input required for OL production } \\
\cline { 2 - 7 } Cell source & E20 & P0 & P1 & \multicolumn{1}{c}{ P7 } & P17 & \multicolumn{1}{l}{12 wk } \\
\hline Inner cerebellum & $233 \pm 230$ & 500 & $233 \pm 230$ & 500 & 10,000 & $>10,000$ \\
Outer cerebellum & $233 \pm 230$ & $300 \pm 282$ & $75 \pm 353$ & 1000 & 5,000 & $>10,000$
\end{tabular}

Cerebella were isolated from different age rats and further dissected. "Inner cerebellum" consisted of the superior medullary velum, cerebellar peduncles, and central cerebellum. "Outer cerebellum" consisted of the extremes of the folia from just distal to the start of the invaginations to the tip of the folia. Six cultures were initiated with various cell inputs for each data point, allowed to develop for $15 \mathrm{~d}$, and then tested for the presence of OL by CNP immunocytochemistry. The input required to producc $O L$ in all six culturcs was detcrmined. This valuc represents the relative ability of the population to generate OL clones. The data are the average of two experiments. For the adult tissue, even 10,000 cells gave rise to OL-containing cultures only $33-50 \%$ of the time.

the telencephalon are pro-oligodendroblasts (Gard and Pfeiffer, 1989) and thus account for $\sim 50 \%$ of this pool.

\section{Localization of $O L$ precursors in developing cerebellum}

The spatial distribution of OL progenitors during cerebellar development was examined. The predominant hypothesis is that ganglioside $\mathrm{G}_{\mathrm{D}_{3}}$-expressing $\left(\mathrm{G}_{\mathrm{D}_{3}}{ }^{+}\right) \mathrm{OL}$ progenitors migrate out from the superior medullary velum over the fourth ventricle and the cerebellar peduncles, into the cerebellum proper, and subsequently out into the folia beginning just before birth (Levine and Goldman, 1988; Reynolds and Wilkin, 1988; Hardy and Reynolds, 1991). This is based on the appearance of a developmental wave of $\mathrm{G}_{\mathrm{D} 3}{ }^{+}$cells, believed to bc OL precursors, from the base of the cerebellum outward toward the folia. An alternative interpretation of the same data is that cells of an unknown phenotype have already migrated out to the folia and subsequently differentiate into a $\mathrm{G}_{\mathrm{D} 3}{ }^{+}$phenotype in a similar wave. We have investigated this question by determining the number of cells from suspensions derived from either the cerebellar folia or the ventral cerebellar structures required to consistently produce OL clone-positive cultures as a function of age. If $\mathrm{G}_{\mathrm{D} 3}+$ cells are the major source of $\mathrm{OL}$ in the cerebellum, then the relative numbers of precursors should parallel the presence of $\mathrm{G}_{\mathrm{D} 3}{ }^{+}$cells. Alternatively, if the folia are already populated with phenotypically undefined OL precursors, then the outer foliar population will give rise to $\mathrm{OL}$ independent of $\mathrm{G}_{\mathrm{D} 3}{ }^{+}$ cell numbers in the plating population. At E20 (earliest age tested) and P0, both the distal and proximal cerebellum produced all positive wells from similar cell inputs (Table 3 ). This demonstrates the presence of OL precursors in uniform density throughout the cerebellum at times when very few $\mathrm{G}_{\mathrm{D}_{3}}{ }^{+}$cells are found out in the folia. As the cerebellum continues to develop, the number of $\mathrm{OL}$ precursors drops (P1-P17) but remained consistently uniform for inner and outer cerebellum populations. OL precursors were also detectable in the adult cerebellum, but were relatively rare, requiring greater than 10,000 cells to generate only three of six $\mathrm{OL}^{+}$cultures.

\section{Discussion}

We have developed a retrospective analysis circumventing the need for specific markers of OL precursors in order to investigate early OL development in the rat brain. Phenotypically undefined populations were allowed to develop in a culture system designed to promote OL production with high efficiency. The presence of a cell in the initial population with the ability to producc offspring capable of differentiating into OL was demonstrated by using well characterized, OL lineage-specific immunological reagents after allowing time for proliferation and differentiation.
This approach was used to estimate the pool size of OL progenitors present perinatally, and to localize them within the developing cerebellum.

The results provide two major new insights into the ontogeny of the OL lineage. First, contrary to previous estimates, we have demonstrated that large numbers $\left(>10^{6}\right.$ at $\left.\mathrm{P} 0\right)$ of cells committed to the OL lineage are present in perinatal brain, enough to generate a full adult complement of OL without a period of exceptionally rapid cell division. Second, regions of the cerebellum previously thought to be devoid of OL precursors are populated with a significant pool of cells able to generate OL clones in our culture system. Thus, as early as E20, at least one type of OL prccursor has migrated out of germinal zones into the outer folia. Further investigations and the advent of novel lineage-specific reagents should be able to clarify the time and place at which OL precursors become committed and begin to populate the CNS.

\section{Quantitation of $O L$ precursor pools}

Estimates of the OL precursor pool size in perinatal rat brain by LDA were initially performed by Barbarese et al. (1981) using a radioimmunoassay for myelin basic protein to identify positive events. They concluded that only a small pool of 400-600 cells was present at birth, noting that the plating efficiency in that study was an unknown factor. Gard et al. (1988), using an improved dissociation method, increased the estimated size of the pool of OL progenitors to between 6000 and 8000 cells per brain, a value that still suggested that the progenitor pool was small relative to the number of mature OL which could be directly visualized later in development. From these initial estimates, between 17 and 13 rounds of proliferation, respectively, would have been needed to generate the 60 million OL estimated to be present in adult brain (Pfeiffer et al., 1993). However, in retrospect, both of these former studies most likely yielded nonlinear relationships between $\ln F_{o}$ and $u$. Therefore, a critical point to recognize in this study is the linearity of the data, demonstrating that single-hit events, that is, $100 \%$ plating efficiency for OL precursors, were being observed.

A dramatic improvement in the plating efficiency at limiting dilution, adherence to the requirement that only a single cell type be limiting, and an improved assay for the detection of mature $\mathrm{OL}$ in the microcultures have led to a substantially higher prediction of the precursor pool size. Further, by directly testing the developmental potential of specific phenotypic stages of the OL lineage, it is clear that these estimates arc restricted to cells previously shown to be proliferative in vivo (Reynolds and Wilkin, 1989; Gard and Pfeiffer, 1990; Warrington and Pfeiffer, 1992). The data predict that at E21 there are $\sim 2 \times 10^{5}$ 
OL progenitors in the whole brain, and by $\mathrm{PO}$ the pool has increased to $\sim 1 \times 10^{6}$ cells. This number of OL precursors requires only about eight rounds of cell division to produce the adult OL complement, a result attainable with a relatively unremarkable doubling time of $24-36 \mathrm{hr}$ in $\sim 10 \mathrm{~d}$.

Pro-oligodendroblasts are the earliest $\mathrm{OL}$ precursors that can be definitively identified in a complex mixture of neural cells using immunological reagents (Gard and Pfeiffer, 1989). Earlier developmentally regulated antigens are expressed by a number of different cell types, including neuroblasts and immature neurons (Eisenbarth et al., 1979; Goldman et al., 1984). Prior to birth (E21) it was not possible to detect pro-oligodendroblasts or OL in the telencephalon by direct immunolabeling (Gard and Pfeiffer, 1989). Therefore, the total telencephalon OL precursor pool detected by LDA at this age, $\sim 1 \times 10^{5}$ cells, must consist of phenotypically undefined cells of the OL lineage. At P0 $\sim 1.5$ $\times 10^{5}$, pro-oligodendroblasts appear in the telencephalon (Gard and Pfeiffer, 1989), a time when a pool of $\sim 2.5 \times 10^{5} \mathrm{OL}$ precursors is predicted to be present by LDA. These data also demonstrate the presence of substantial numbers of phenotypically undefined cells with the ability to differentiate into OL in our culture system.

Myelinogenesis occurs along a caudal to rostral gradient in the mammalian CNS. This results in the appearance of mature myelin in the brainstem at a time when the telencephalon has not yet initiated identifiable myelin synthesis (Verity and Campagnoni, 1988; Shiota et al., 1989). A cell population derived from whole brain will therefore be more developmentally heterogeneous and, on the average, more developmentally advanced than one generated from an age-matched telencephalon. The greater increase in OL progenitor frequency from E21 to $\mathrm{P} 0$ in the whole brain, $\sim 5$-fold (1 progenitor in 365 total cells at E21 increasing to 1 in 74 cells at P0) compared to that in the telencephalon, $\sim 2.5$-fold ( 1 in 298 at E21 increasing to 1 in 115 at $\mathrm{P} 0$ ), is consistent with this developmental progression. Increases in OL precursor frequency represent the net result of positive contributions from both proliferation and birth (i.e., commitment to the OL lineage) of new precursors, and the negative effect of their differentiation to postmitotic OL (negligible at perinatal ages). The observed increase in precursor numbers ( $\sim 5$-fold) during the $24 \mathrm{hr}$ from E21 to P0 is more than can reasonably be accounted for by proliferation (assuming an unremarkable doubling time of 18-24 hr). Thus, it appears that lineage commitment provides a major contribution to $\mathrm{OL}$ ontogeny at the time of birth.

\section{$O L$ precursor localization in the developing cerebellum}

In order to determine if regions of the developing brain that contain few if any OL lineage cells identified by current methods were actually populated by cells with the ability to give rise to OL, we produced cultures from single-cell suspensions of cerebellar germinal zones and from the adjacent folia at a number of different ages. Previous models for the population of the cerebellum with OL suggested OL progenitors expressing the $\mathrm{G}_{\mathrm{D} 3}$ ganglioside migrated out of germinal zones, first populating the superior medullary velum before appearing in distal foliar locations, possibly undergoing asymmetric divisions along the way, to generate a population of locally proliferating $\mathrm{O}^{+}$prooligodendroblasts (Curtis et al., 1988; Levine and Goldman, 1988; Reynolds and Wilkin, 1988; Hardy and Reynolds, 1991). Accordingly, one would expect there to be an age when few OL progenitors are present in the cerebellar periphery and many are already present near the cerebellar base, an intermediate developmental window when progenitors were present throughout the cerebellum, and older ages where OL progenitors were present predominately in the periphery because myelination was complete in ventral structures. However, we find that the germinal zone-distal regions are already populated with OL precursors, as early as E20, in numbers large enough to give rise to the full complement of OL seen at later times. Further, there is no clear trend of a developmental gradient of OL precursors when comparing cerebellar areas distal and proximal to the presumptive zones of germination by our retrospective bioassay. The cells simply became more scarce with development as differentiation into postmitotic OL continued in vivo.

Recently, Levine et al. (1993) found cells expressing the NG2 chondroitin-sulfate proteoglycan scattered throughout the embryonic cerebellum. Many of the cells transiently coexpress $G_{D 3}$, and studies in vitro suggest that a significant number of them are OL progenitors. These cells increased in density approximately 10-fold from E19 to P0; however the same population did not become highly proliferative until P3. This discrepancy strongly suggests that the increase in $\mathrm{NG}_{2}{ }^{+}$cell density is from a pool of cells already occupying the entire cerebellum differentiating into a $\mathrm{NG}^{+}$population. A limitation of this study is that NG2 expression is not specific to the OL lineage, but assuming that the majority of the NG2 labeled cells are OL progenitors, it is interesting to note that the brain populations detected by LDA increased in a similarly rapid fashion from E21 to P0. It now seems probable that the population of the cerebellum by a migratory $\mathrm{G}_{\mathrm{D} 3}{ }^{+}$cell is too simple a model to explain the present data.

One possible scenario is that OL precursors exist as subtypes such that any individual marker, for example, PDGF- $\alpha$ R RNA expression (Pringle et al., 1992), or DM20/PLP RNA expression (Ikenaka et al., 1992; Timsit et al., 1992), detects a subset of the total pool expressing that marker during the developmental window assayed. Further variations could exist if different regions of the CNS are populated by cells with subtle differences in gene expression, yet are functionally identical. Our retrospective assay is independent of markers and quantitates all the cells with the potential to generate OL. Thus, it is not surprising that we demonstrate the presence of large numbers of precursors in the same tissue where only a paucity of cells are labeled with any particular reagent. Additional experiments are needed to determine exactly when OL precursors infiltrate the developing cerebellum and if there are different subtypes of thesc cclls.

The type of retrospective analysis we have described should be applicable to a broad range of lineages where definitive precursor-specific reagents are unavailable. A similar approach has recently been used to identify a pool of phenotypically undefined microglial precursors in the developing mouse neopallium (Richardson et al., 1993). Different frequencies were generated by altering the growth conditions with the addition of trophic factors, leading to the suggestion that some plasticity exists in that lineage. Future analyses of the OL lineage can now be extended to early development, in order to elucidate the primary events in the process of myelinogenesis.

\section{References}

Abney ER, Bartlett PF, Raff MC (1981) Astrocytes, ependymal cells, and oligodendrocytes develop on schedule in dissociated cell cultures of embryonic rat brain. Dev Biol 83:301-310.

Bansal R, Pfeiffer SE (1985) Developmental expression of $2^{\prime}, 3^{\prime}$-cyclic 
nucleotide $3^{\prime}$-phosphohydrolase in dissociated fetal rat brain cultures and rat brain. J Neurosci Res 14:21-34.

Bansal R, Gard AL, Pfeiffer SE (1988) Stimulation of oligodendrocyte differentiation in culture by growth in the presence of a monoclonal antibody to sulfated glycolipid. J Neurosci Res 21:260-267.

Bansal R, Warrington AE, Gard AL, Ranscht B, Pfeiffer SE (1989) Multiple and novel specificities of monoclonal antibodies $\mathrm{O} 1, \mathrm{O} 4$, and $\mathrm{R}-\mathrm{mAb}$ used in the analysis of oligodendrocyte development. J Neurosci Res 24:548-557.

Bansal R, Stefansson K, Pfeiffer SE (1992) Pro-oligodendroblast antigen, a developmental antigen expressed by A007/O4-positive oligodendrocyte progenitors prior to the appearance of sulfatide and galactocerebroside. J Neurochem 58:2221-2229.

Barbarese E, Pfeiffer SE, Carson JH (1983) Progenitors of oligodendrocytes: limiting dilution analysis in fetal rat brain culture. Dev Biol 96:84-88.

Correa FMA, Guilhaume SS, Saavedra JM (1988) A simple two-step immunocytochemical method using protein A-peroxidase to stain immunoreactive cell antigens. Brain Res 448:192-197.

Curtis R, Cohen J, Fok-Seang J, Hanley MR, Gregson NA, Reynolds $\mathrm{R}$, Wilkin GP (1988) Development of macroglial cells in rat cerebellum. I. Use of antibodies to follow early in vitro development and migration of oligodendrocytes. J Neurocytol 17:43-54.

Dubois C, Manuguerra J, Hauttecoeur B, Maze J (1990) Monoclonal antibody A2B5, which detects cell surface antigens, binds to ganglioside $\left.\mathrm{G}_{\mathrm{T} 3}\left(\mathrm{II}^{3} \text { (NeuAc) }\right)_{3} \mathrm{LacCer}\right)$ and to its $9-\mathrm{O}$-acetylated derivative. J Biol Chem 265:2797-2803.

Dubois-Dalcq M (1987) Characterization of a slowly proliferative cell along the oligodendrocyte differentiation pathway. EMBO J 6:25872595.

Eisenbarth GS, Walsh FS, Nirenberg M (1979) Monoclonal antibody to a plasma membrane antigen of neurons. Proc Natl Acad Sci USA 76:4913-4917.

Gard AL, Pfeiffer SE (1989) Oligodendrocyte progenitors isolated directly from developing telencephalon at a specific phenotypic stage: myelinogenic potential in a defined environment. Development 106: 119-132.

Gard AL, Pfeiffer SE (1990) Two proliferative stages of the oligodendrocyte lineage (A2B5+ ${ }^{+} 4^{-}$and $\mathrm{O}^{+} \mathrm{GalC}^{-}$) under different mitogenic control. Neuron 5:615-625.

Gard AL, Warrington AE, Pfeiffer SE (1988) Direct microculture enzyme-linked immunosorbent assay for studying neural cells: oligodendrocytes. J Neurosci Res 20:46-53.

Goldman JE, Hirano M, Yu RK, Seyfried TN (1984) $\mathrm{G}_{\mathrm{D} 3}$ ganglioside is a glycolipid characteristic of immature neuroectodermal cells. $\mathrm{J}$ Neuroimmunol 7:170-192.

Gonye GE, Gard AL, Pfeiffer SE (1989) Quantitation of oligodendroblast pool size in developing rat brain. Trans Am Soc Neurochem 20:249.

Grinspan JB, Stern JL, Pustilnik SM, Pleasure D (1990) Cerebral white matter contains PDGF-responsive precursors to O2A cells. J Neurosci 10:1866-1873.

Hardy R, Reynolds R (1991) Proliferation and differentiation of rat forebrain oligodendroglial progenitors both in vitro and in vivo. Development 111:1061-1080.

Hart IK, Richardson WD, Heldin C-H, Westermark B, Raff MC (1989) PDGF receptors on cells of the oligodendrocyte-type-2 astrocyte $(0$ 2A) lineage. Development 105:595-603.

Ikenaka K, Kagawa T, Mikoshiba K (1992) Selective expression of DM-20, an alternatively spliced myelin proteolipid gene product, in developing nervous system and in non-glial cells. J Neurochem 58: 2248-2253.

Johnson GD, Davison RS, McNamee KC, Russell G, Goodwin D, Holborow EJ (1982) Fading on immunofluorescence during microscopy: a study of the phenomenon and its remedy. J Immunol Methods 55:231-242.
Lee V, Wu HL, Schlaepfer WW (1984) Monoclonal antibodies to gelexcised glial filament protein and their reactivity with other intermediate filament proteins. J Neurochem 42:25-32.

Lefkovitz I, Waldmann $\mathrm{H}$ (1979) Limiting dilution analysis of cells in the immune system. Cambridge: Cambridge UP.

Levine JM, Stincone F, Lee Y-S (1993) Development and differentiation of glial precursor cells in the rat cerebellum. Glia 7:307-321.

Levine SM, Goldman JE (1988) Spatial and temporal patterns of oligodendrocyte differentiation in rat cerebrum and cerebellum. J Comp Neurol 277:441-455.

Luskin MB, Pearlman AL, Sanes JR (1988) Cell lineage in the cerebral cortex of the mouse studied in vivo and in vitro with a recombinant rctrovirus. Neuron 1:635-647.

McCarthy KD, DeVellis J (1980) Preparation of separate astroglial and oligodendroglial cell cultures from rat cerebral tissue. J Cell Biol 85:890-902.

McKinnon RD, Matsui T, Dubois-Dalcq M, Aaronson SA (1990) FGF modulates the PDGF-driven pathway of oligodendrocyte development. Neuron 5:603-614.

Noble M, Murray K (1984) Purified astrocytes promote the in vitro division of a bipotential glial progenitor cell. EMBO J 3:2243-2247.

Pfeiffer SE, Warrington AE, Bansal R (1993) The oligodendrocyte and its many cellular processes. Trends Cell Biol 3:191-197.

Pringle NP, Mudhar HS, Collarini EJ, Richardson WD (1992) PDGF receptors in the rat CNS: during late neurogenesis, PDGF alphareceptor expression appears to be restricted to glial cells of the oligodendrocyte lineage. Development 115:535-551.

Raff MC, Miller RH, Noble M (1983) A glial progenitor cell that develops in vitro into an astrocyte or an oligodendrocyte depending on the culture medium. Nature 303:389-396.

Raff MC, Abney ER, Fok-Seang J (1985) Reconstitution of a developmental clock in vitro: a critical role for astrocytes in the timing of oligodendrocyte differentiation. Cell 42:61-69.

Reynolds R, Wilkin GP (1988) Development of macroglial cells in rat cerebellum II. An in situ immunohistochemical study of oligodendroglial lineage from precursor to mature myelinating cell. Development 102:409-425.

Richardson A, Hao C, Fedoroff S (1993) Microglial progenitor cells: a subpopulation in cultures of mouse neopallial astroglia. Glia 7:2533.

Sharrock CEM, Kaminski E, Man S (1990) Limiting dilution analysis of human T cells: a useful clinical tool. Immunol Today 11:281-286.

Shiota C, Miura M, Mikoshiba K (1989) Developmental profile and differential localization of $m$ RNAs of myelin proteins (MBP and PLP) in oligodendrocytes in the brain and in culture. Dev Brain Res 45: 83-94.

Sommer I, Schachner M (1982) Cells that are O4 antigen-positive and $\mathrm{O} 1$ antigen-negative differentiate into $\mathrm{O} 1$ antigen-positive oligodendrocytes. Neurosci Lett 29:183-188.

Timsit SG, Bally-Cuif L, Colman DR, Zalc B (1992) DM-20 mRNA is expressed during the embryonic development of the nervous system of the mouse. Neuroscience $58: 1172-1175$.

Verity AN, Campagnoni AT (1988) Regional expression of myelin protein genes in the developing mouse brain: in situ hybridization studies. J Neurosci Res 21:238-248.

Warrington AE, Pfeiffer SE (1992) Differentiation and proliferation of $\mathrm{O}^{+}$oligodendrocytes in postnatal rat cerebellum: analysis in unfixed tissue slices using anti-glycolipid antibodies. J Neurosci Res 33: 338-353.

Warrington AE, Barbarese E, Pfeiffer SE (1993) Differential myelinogenic capacity of specific developmental stages of the oligodendrocyte lineage upon transplantation into hypomyelinating hosts. J Neurosci Res 34:1-13 